\title{
Haemodynamic advantages of combined alpha-blockade and beta-blockade over beta-blockade alone in patients with coronary heart disease
}

\author{
S H TAYLOR, B SILKE, G I C NELSON, R C OKOLI, R C AHUJA
}

\begin{abstract}
The acute haemodynamic effects of beta-blockade with propranolol and combined alpha-blockade and betablockade with labetalol were compared in a randomised study in 12 patients with coronary artery disease proved by angiography. Propranolol induced significantly greater depression of left ventricular function both at rest and during exercise than labetalol. This difference was probably attributable to the vasodilator activity of labetalol and the associated reduction in afterload offsetting the haemodynamic disadvantages of blockade of cardiac beta-adrenoceptors alone.

The haemodynamic advantages of combined alphablockade and beta-blockade over beta-blockade alone may thus have therapeutic implications for the use of these treatments in patients with coronary heart disease.
\end{abstract}

\section{Introduction}

Beta-blocking drugs are commonly used in coronary heart disease as symptomatic treatment for patients with angina pectoris $^{12}$ and more recently have been advocated for the secondary prevention of myocardial infarction. ${ }^{3-7}$ By reducing heart rate and myocardial contractility ${ }^{8}$ they reduce myocardial oxygen consumption, but these benefits tend to be offset by a concomitant increase in left ventricular afterload. ${ }^{9}$ This stems from two sources. Firstly, blockade of myocardial beta ${ }_{1}$-receptors results in an increase in left ventricular volume. ${ }^{10-12}$ Secondly, blockade of vasodilator beta $_{2}$-adrenoceptors in the peripheral circulation directly increases systemic vascular resistance and

University Department of Cardiovascular Studies and Department of Medical Cardiology, General Infirmary, Leeds LS1 3EX

S H TAYLOR, MD, FRCPED, senior lecturer and deputy director B SILKE, MD, MRCPI, research fellow and honorary senior registrar G I C NELSON, MB, FRACP, research fellow and honorary senior registrar R C OKOLI, MB, CHB, research fellow

R C AHUJA, MB, CHB, research fellow aortic impedance and this is further augmented by the reflex vasoconstriction resulting from the reduction in cardiac output. ${ }^{13}$ Logically therefore, simultaneous reduction in afterload by vasodilatation could be expected to counter the depression of left ventricular pumping function resulting from beta-blockade alone. This hypothesis was tested by comparing the haemodynamic effects of equivalent beta-blocking doses of propranolol and labetalol, a drug which combines alpha-blocking and betablocking properties, ${ }^{14}$ in patients with stable coronary heart disease.

\section{Patients and methods}

Twelve men aged 25-64 years, with symptomatic, electrocardiographic, and angiographic evidence of coronary heart disease were studied. All were normotensive and in sinus rhythm without clinical or radiographic signs of left ventricular failure. None had any clinical contraindications to the use of beta-blocking drugs and none were receiving drugs other than short-acting nitrates. Informed consent was given by all patients and the investigation agreed by the hospital ethics committee.

Patients were allocated at random to receive propranolol or labetalol (six in each group). A control period was started with four minutes' supine bicycle exercise at the predetermined symptom-limiting load (25-50 W); haemodynamic measurements were made during the final minute of exercise. When circulatory variables had restabilised, resting measurements were made for four minutes, after which propranolol or labetalol in equivalent beta-blocking doses ${ }^{15}$ were infused intravenously over 20 minutes to give final cumulative doses of $16 \mathrm{mg}$ for propranolol and $80 \mathrm{mg}$ for labetalol respectively. Haemodynamic measurements were recorded during the four minutes immediately after completion of the intravenous infusion and bicycle exercise was then repeated at the same workload. Heart rate was measured from the electrocardiogram, systemic arterial and pulmonary vascular pressures were externally transduced, and cardiac output was measured by computer integration of triplicate right-heart thermal-dilution curves. Pulmonary artery occluded pressure was taken as an index of left ventricular filling pressure, and systemic vascular resistance was calculated by conventional means. Probability of statistical significance of differences between data before and after taking drugs was tested by analysis of variance of repeated measurements. 1617 


\section{Results}

There was comparable distribution between the two groups in terms of the severity of symptoms and extent of angiographic coronary artery disease. Left ventricular performance, however, in terms of the relation between left ventricular filling pressure and cardiac output was impaired to a greater extent in the patients allocated at random to receive labetalol than in those allocated to receive propranolol.

\section{COMPARISON OF HAEMODYNAMIC EFFECTS OF PROPRANOLOL AND} LABETALOL

After propranolol the systemic blood pressure was unchanged at rest but significantly reduced during exercise compared with control values. Cardiac output and heart rate were reduced and pulmonary artery occluded pressure and systemic vascular resistance significantly increased, both at rest and during exercise (see table).

After labetalol the systemic blood pressure and systemic vascular resistance were significantly reduced, both at rest and during exercise, compared with results before taking the drugs. Cardiac output at rest was increased and the response to exercise unchanged. Heart rate was unchanged compared with control values both at rest and during exercise. The pulmonary artery occluded pressure was unchanged at rest but increased during exercise after labetalol (see table).

Considering the rest and exercise relation between pulmonary artery occluded pressure and cardiac output, the left ventricular function curve was significantly shifted to the right after propranolol $(p<0.01)$ but unchanged after labetalol, despite its greater initial depression in those taking labetalol (see figure).

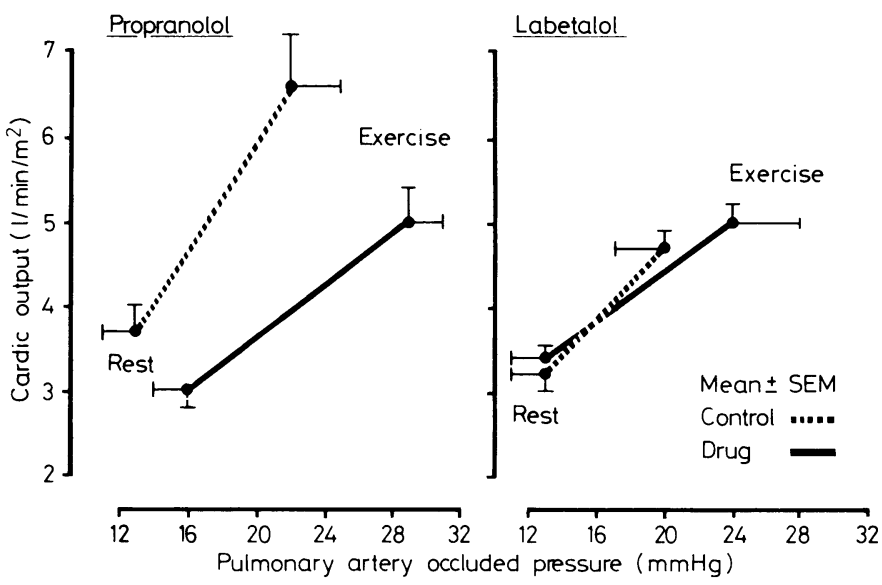

Comparison of effects of intravenous propranolol and labetalol in equivalen beta-blocking doses on left ventricular function curves of patients with coronary heart disease.

\section{Discussion}

These studies clearly show the previously reported depression of left ventricular pumping function after beta-blockade, ${ }^{11} 12$ particularly during exercise, ${ }^{18} 19$ in patients with coronary heart disease. Our results also support the validity of the haemodynamic argument on which this comparative study was based - namely, that concomitant dilatation of peripheral arterial resistance vessels affords a means of countering the depression of left ventricular function that is associated with beta-blockade alone. In our patients, the relation between the filling pressure of the left ventricle and its pumped output was largely unimpaired after combined alpha-blockade and beta-blockade with labetalol compared with the substantial depression that followed beta-blockade alone with propranolol. This contrasting effect of the two drugs on left ventricular pumping ability was most probably related to the reduction in pressure work induced by the vasodilator component of labetalol over and above its betablocking activity.

These results are instructive, but they must be interpreted with caution. The results of acute intervention studies may not always reflect the quantitative effects of long-term treatment. Nevertheless, previous haemodynamic studies with these sympathomimetic blocking drugs have shown similar qualitative changes after their acute intravenous and chronic oral administration. ${ }^{20}$ It is also difficult to arrive at comparative physiological beta-blocking doses of these drugs when one possesses a vasodilator component. The doses we used, however, have been shown to possess about an equal degree of inhibition of isoprenaline tachycardia in man. ${ }^{15}$

From the clinical viewpoint, there is no doubt that betablocking drugs offer a clinically effective treatment in many patients with exercise-induced angina pectoris. Our results suggest that the symptomatic efficacy of such treatment may be enhanced by the addition of alpha-blockade. The implication of these findings in patients undergoing long-term treatment with beta-blocking drugs for the secondary prevention of myocardial infarction is also of interest. Beta-blocking drugs aggravate the loss of myocardial reserve present in many of these patients. ${ }^{21}$ Our results suggest that in patients in whom beta-blocking drugs are indicated, concomitant vasodilator or alpha-blockade may afford a method of offsetting their haemodynamic disadvantages and enhancing their therapeutic activity.

We thank Dr M Hussain and the technical and nursing staff of the Departments of Cardiovascular Studies and Medical Cardiology for their help with these studies, and Miss Anne Storey for statistical advice. This study was supported by grants from Glaxo Operations (UK) Ltd and the Yorkshire Regional Hospital Board.

\section{References}

1 Prichard BNC, Aellig WH, Richardson GA. The action of intravenous oxprenolol, practolol, propranolol and sotalol on acute exercise tolerance in angina pectoris; the effect on heart rate and the electrocardiogram. Postgrad Med $\mathcal{F} 1970 ; 46$,suppl:77-83.

2 Thadani U, Davidson C, Singleton W, Taylor SH. Comparison of the immediate effects of five beta-adrenoceptor blocking drugs with differen ancillary properties in angina pectoris. $N$ Engl f Med 1979;300:750-5.

${ }^{3}$ Multicentre International Study. Reduction in mortality after myocardia infarction with long-term beta-adrenoceptor blockade. Br Med $\mathcal{F} 1977$; ii $419-21$.

Haemodynamic effects of propranolol and labetalol in 12 patients with coronary artery disease. Figures are means \pm SEM

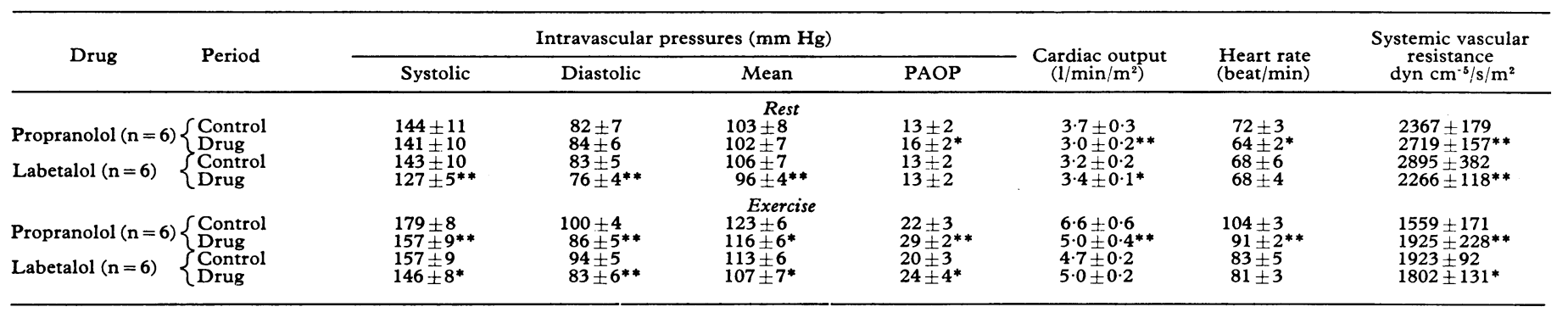

PAOP $=$ Pulmonary artery occluded pressure.

Drug $v$ control $* \mathrm{p}<0.05, * * \mathrm{p}<0.01$ 
4 Yusef S, Ramsdale D, Peto R, et al. Early intravenous atenolol treatment in suspected acute myocardial infarction. Lancet 1980 ;ii:273-6.

${ }^{5}$ Norwegian Multicentre Study Group. Timolol-induced reduction in mortality and reinfarction in patients surviving acute myocardial infarction. N Engl F Med $1981 ; 304: 801-7$.

${ }^{6}$ Beta-Blocker Heart Attack Study Group. The beta-blocker heart attack trial-preliminary report. $\mathcal{F} A M A 1981 ; \mathbf{2 4 6}: 2073-4$.

' Hansteen V, Moinichen E, Lorentsen E, et al. One year's treatment with propranolol after myocardial infarction: preliminary report of Norwegian multicentre trial. Br Med f 1982;284:155-60.

${ }^{8}$ Sonnenblick EH, Ross J, Covell JW, Kaiser GA, Braunwald E. Velocity of contraction as a determinant of myocardial oxygen consumption. Am $\mathcal{F}$ Physiol 1965;209:919-27.

${ }^{9}$ Braunwald E. Thirteenth Bowditch lecture. The determinants of myocardial oxygen consumption. Physiologist 1969;12:65-93.

10 Chamberlain D. Effects of beta-adrenergic blockade on heart size. Am $\mathcal{F}$ Cardiol 1966;18:321-8.

11 Coltart DJ, Alderman EL, Robinson SC, Harrison DC. Effect of propranolol on left ventricular function, segmental wall motion and diastolic pressure-volume relation in man. Br Heart $\mathcal{7}$ 1975;37:357-64.

12 Dehmer GJ, Falkoff M, Lewis SE, Hillis LD, Parkey RW, Willerson JT. Effect of oral propranolol on rest and exercise left ventricular ejection fraction, volumes, and segmental wall motion in patients with angina pectoris. Assessment with equilibrium gated blood pool imaging. $\mathrm{Br}$ Heart $\mathcal{F} 1981 ; 45: 656-6$.
13 White C de B, Udwadia BP. Beta-adrenoceptor blockade and alphaadrenergic potentiation. Br f Clin Pharmacol 1975;2:99-105.

${ }^{14}$ Richards DA, Prichard BNC. Clinical pharmacology of labetalol. $\mathrm{Br} \mathcal{F}$ Clin Pharmacol 1979;8:89-93.

15 Richards DA, Prichard BNC, Dobbs RJ. Adrenoceptor blockade of the circulatory responses to intravenous isoproterenol. Clin Pharmacol Ther $1978 ; 24: 264-73$.

${ }^{16}$ Dixon WJ, Brown MB, eds. Biomedical computer programme-“P” series. Berkeley: University of California Press, 1979:540-80.

17 Winer BJ. Statistical principles in experimental design. 2nd ed. New York: McGraw-Hill, 1971:197-200.

${ }^{18}$ Reale A, Nigri A, Gioffre PA, Motolese M. Acute influence of different beta-blocking agents upon left heart haemodynamics at rest and during exercise in patients with coronary heart disease. Eur $\mathcal{F}$ Cardiol 1979;9: 101-9.

19 Taylor SH, Silke B, Lee PS. Intravenous beta-blockade in coronary heart disease: is cardioselectivity or intrinsic sympathomimetic activity haemodynamically useful ? $N$ Engl f Med $1982 ; 306: 631-5$.

${ }^{20}$ Koch G. Cardiovascular dynamics after acute and long-term alpha- and beta-adrenoceptor blockade at rest, supine and standing, and during exercise, Br 7 Clin Pharmacol 1979;8:101-5.

21 Taylor SH, Silke B. Haemodynamic effects of beta-blockade in ischaemic heart failure. Lancet 1981 ;ii:835-7.

(Accepted 6 May 1982)

\title{
Maternal anti-D concentrations and outcome in rhesus haemolytic disease of the newborn
}

\author{
P BOWELL, J S WAINSCOAT, T E A PETO, H H GUNSON
}

\begin{abstract}
The relation between maternal anti-D concentrations, measured against the British working standard, and outcome of rhesus-sensitised pregnancies was studied. There is a clear relation between increasing anti-D concentrations and the chance of a severely affected baby. Of those pregnancies (78) where serial anti-D concentrations remained below $4 \mathrm{IU} / \mathrm{ml}$, no baby had a cord haemoglobin below $10 \mathrm{~g} / \mathrm{dl}$ and three had exchange transfusions. In contrast, of those mothers (106) with anti-D concentrations above $4 \mathrm{IU} / \mathrm{ml}, 23 \mathrm{had}$ babies with a cord haemoglobin below $10 \mathrm{~g} / \mathrm{dl}$ and 79 babies had exchange transfusions.

It is suggested that those pregnancies where anti-D concentrations remain below $4 \mathrm{IU} / \mathrm{ml}$ represent a relatively safe group in which amniocentesis may be avoided.
\end{abstract}

\section{Introduction}

In spite of prophylaxis, rhesus haemolytic disease of the newborn remains an appreciable clinical problem. ${ }^{12}$ The management of affected pregnancies is helped by a prediction of outcome, which

\footnotetext{
Oxford Regional Blood Transfusion Centre, John Radcliffe Hospital, Headington, Oxford OX3 9DU

P BOWELL, FIMLS, chief medical laboratory scientific officer

H H GUNSON, FRCPATH, DSC, director (present position: director, Northwest Regional Transfusion Service, Manchester)

Nuffield Department of Clinical Medicine, John Radcliffe Hospital, Headington, Oxford OX3 9DU

J S WAINSCOAT, MRCP, MRCPATH, MRC training fellow

T E A PETO, MRCP, DPHIL, MRC training fellow
}

is conventionally based on previous history, some measure of maternal anti-D potency, and, in selected cases, examination of amniotic fluid. The estimation and interpretation of anti-D potency has been problematic for several reasons: the older manual titration method gives poor reproducibility, ${ }^{3}$ the early automated method of quantification ${ }^{4}$ required several modifications, ${ }^{56}$ and different anti-D standards have been used in Britain for the automated quantification method. A British anti-D working standard (coded 72/229) was established in 1975, however, and virtually all laboratories have now adopted this preparation for determination of antenatal anti-D concentrations.

We examined the relation between maternal anti-D concentrations and outcome of rhesus-sensitised pregnancies in the Oxford region. This is the first such study to report anti-D concentrations measured, with the above modifications, directly against the British anti-D working standard.

\section{Patients and methods}

From 1977 to 1980 all pregnant women in the Oxford region were screened for red cell antibodies, principally at the Oxford Regional Transfusion Centre but also at several of the district hospitals. During this period 380 women were found to have anti-D antibodies: details of relevant investigations were routinely sent to the Oxford Regional Transfusion Centre and sufficient data for study was available from 260 patients. The remaining 120 were excluded for the following reasons: only one anti-D concentration determined (60), anti-D detectable by enzyme-modified cells only (level $<0.05 \mathrm{IU} / \mathrm{ml}$ ) (35), insufficient information (14), incidental abortions (six), anti-D found only at birth (four), rhesus-positive patient with $0.75 \mathrm{IU} / \mathrm{ml}$ anti-D (one)

Cord haemoglobin and bilirubin concentrations were measured, $\mathrm{ABO}$ and rhesus blood group determined, and direct antiglobulin tests performed in hospital laboratories by standard methods. Automated anti-D quantification was performed using an autoanalyser (Technicon) and based on the method of Marsh et al $l^{4}$ using the modifications recommended by Gunson et al. ${ }^{5} 6$ In addition, a cell concen- 